\title{
1 Recovery of sevoflurane anesthetic gas using an organosilica 2 membrane in conjunction with a scavenging system
}

3 Liang Liu ${ }^{\mathrm{a}}$, Forbes McGain ${ }^{\mathrm{b}}$ and Sandra E. Kentish ${ }^{* a}$

4

5

aDepartment of Chemical Engineering, The University of Melbourne, Vic. 3010, Australia.

${ }^{\text {b}}$ Department of Anaesthesia and Intensive Care, Western Health, Vic. 3054, Australia.

\section{Abstract}

Approximately 95\% of the anesthetic gas administered to a patient is exhaled and ultimately released to the atmosphere. Most anaesthetic gases have high global warming potential and so this approach adds significantly to the global greenhouse gas footprint. In this work we develop a feasible means to capture such an anaesthetic gas (sevoflurane) before it is released to the hospital scavenging system, so that it is retained within the anaesthetic circuit. Sevoflurane is retained using a microporous 1,2bis(triethoxysilyl)ethane (BTESE) membrane prepared by a sol-gel method. The use of a ceramic membrane facilities sanitisation at high temperatures. A rapid thermal processing (RTP) technique is employed to reduce production time and to create a looser organosilica network, resulting in higher gas permeances, compared with the membrane synthesized from conventional thermal processing (CTP). The RTP membrane shows a slight decline in gas permeance when used with a dry mixture of $\mathrm{CO}_{2} / \mathrm{N}_{2} /$ sevoflurane. This permeance falls again under $20 \%$ relative humidity feed conditions but the $\mathrm{CO}_{2} /$ sevoflurane selectivity increases. The membrane performance shows little variation when the relative humidity is further increased. These promising results demonstrate that this microporous BTESE membrane has great potential for the recovery of sevoflurane in an anaesthetic application. 
Volatile anesthetic gases such as desflurane, isoflurane and sevoflurane are widely used in clinical anesthesia. ${ }^{1}$ However, less than 5 vol\% of the patient's total inhaled dose is metabolized. ${ }^{2}$ The exhaled anaesthetic is captured within the hospital scavenging system and ultimately exhausted to the atmosphere. These volatile anesthetic gases are expensive and have high greenhouse warming potentials (GWPs). ${ }^{1,2}$ There are tens of millions of general anaesthetic procedures every year worldwide and so retaining and recycling these anesthetic gases has significant environmental benefits.

In modern anesthetic systems, the air stream is recirculated in a 'circle' breathing circuit to reduce consumption of both oxygen and the anesthetic (Figure 1 (a)). To prevent the accumulation of $\mathrm{CO}_{2}$, soda lime absorbs $\mathrm{CO}_{2}$. Alternative methods to remove expired $\mathrm{CO}_{2}$ has attracted much research, including using new absorbents ${ }^{3}$ or membrane separation. ${ }^{4-6}$ As one example, $13 \mathrm{X}$ molecular sieves have been shown to be effective $\mathrm{CO}_{2}$ absorbers, without the formation of harmful by-products. ${ }^{3}$ Similarly, Wilfart et al. ${ }^{5}$ recently studied a membrane-based device to remove $\mathrm{CO}_{2}$ from anesthesia circuits using a sweep gas.

The use of a $\mathrm{CO}_{2}$ removal device does not eliminate the need for a purge stream from the circuit to maintain pressure control, as fresh gas flow is required for $\mathrm{O}_{2}$ and volatile gas delivery. The hospital vacuum scavenging system is used for this purpose (Figure 1(a)). As 95\% of the anesthetic gas is not metabolized, most is vented to the scavenging system, and thereafter the atmosphere. ${ }^{1}$

49

Various absorbents such as activated carbon, ${ }^{7}$ metal-organic-frameworks, ${ }^{8-10}$ and zeolites ${ }^{11}$ have been studied to explore their potential to capture anesthetic gases. The use of such adsorbents prevents atmospheric pollution by anaesthetic gases and thus adding to global warming. Anaesthetic gas adsorption is also useful in situations where a scavenging system is 
unavailable to remove the gases from the operating room (affecting operating theatre staff), such as in veterinary clinics or less economically developed/remote regions. However, unless the adsorbed anesthetic can be recovered thereafter, it does not reduce the consumption of these gases and hence their cost. Recovery from the adsorbent can be energy intensive and there can be regulatory concerns due to potential biological contamination.

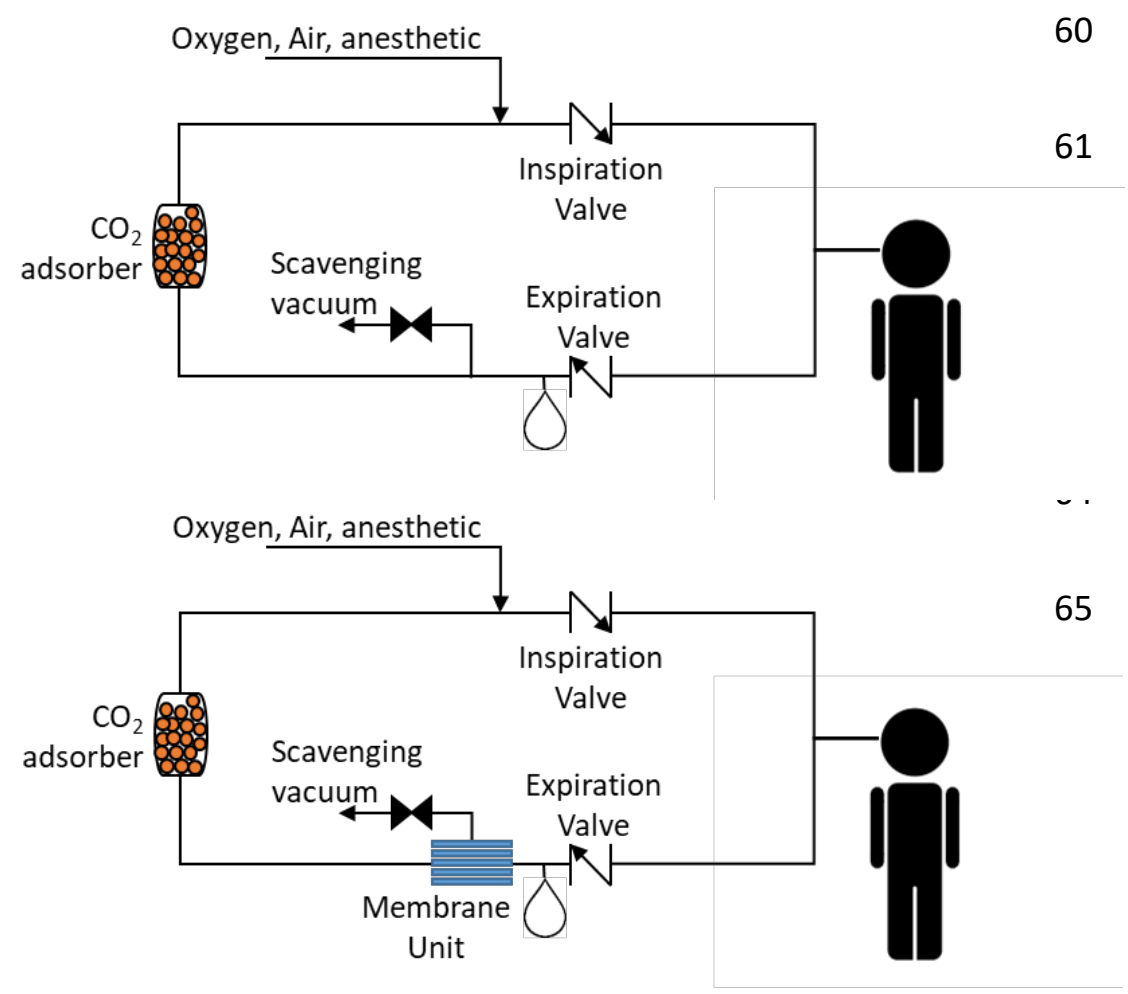

Figure 1: Schematic of (a) a standard anesthetic breathing circuit, and (b) our proposed approach where a membrane is used to retain anesthetics within the circuit.

An alternative approach is to use a size selective membrane that can retain anesthetic gases in the breathing circuit, while allowing other gases $\left(\mathrm{CO}_{2}, \mathrm{O}_{2}, \mathrm{~N}_{2}, \mathrm{H}_{2} \mathrm{O}\right)$ to enter the scavenging system (Figure 1(b)). The approach has a number of advantages. Firstly, the membrane can be run continuously while the adsorbents must be replaced or regenerated. Secondly, the gases can be reused directly by the patient during the operation, reducing the regulatory concerns associated with recycling. Further, the approach utilizes the vacuum provided in the scavenging 
system to provide a pressure driving force for separation. This avoids the need for a sweep gas used in other membrane approaches.

For the approach to be effective, a molecular sieving membrane is needed, as this can retain the larger anesthetic gas molecules such as sevoflurane (molecular weight, MW $200 \mathrm{~g} / \mathrm{mol}$ ) while allowing passage of smaller molecules such as nitrogen (MW 28), oxygen (MW 32) and $\mathrm{CO}_{2}$ (MW 44). A solubility selective membrane will be less effective, as these gases are readily condensable (sevoflurane has a critical temperature of $429 \mathrm{~K}$ ) and so would be readily permeated with other condensable gases such as $\mathrm{CO}_{2}$ (critical temperature 304.2K). An inorganic membrane can provide the necessary molecular sieving capability and also has the advantage that it is resistant to high temperatures and so can be periodically thermally disinfected with hot water or steam, as commonly used for decontaminating other elements of the anesthetic machine. It has already been reported that a DD3R zeolite membrane can effectively retain xenon (an alternate anaesthetic gas) in a $\mathrm{CO}_{2} /$ xenon mixture. ${ }^{12}$ The $\mathrm{CO}_{2}$ permeance was 60 GPU and the $\mathrm{CO}_{2} /$ xenon selectivity was 67 for a wet $\mathrm{CO}_{2} /$ xenon mixture.

In this work, microporous organosilica membranes derived from 1,2-bis(triethoxysilyl)ethane (BTESE) were synthesized by a sol-gel method followed by either a conventional thermal processing (CTP), or a rapid thermal processing (RTP) step to explore BTESE's potential for sevoflurane recovery. Although there are many reports on the gas separation performance of microporous BTESE membranes, most focus on high temperature $\mathrm{H}_{2} / \mathrm{CO}_{2}$ separation. ${ }^{13-15}$ Moreover, a few reports have shown that BTESE membranes also have promising performance for $\mathrm{CO}_{2} / \mathrm{N}_{2}$ separation ${ }^{16}$ and $\mathrm{CO}_{2} / \mathrm{CH}_{4}$ separation. ${ }^{17}$ Due to the presence of Si-C-C-Si groups, BTESE membranes have a slightly larger pore size than conventional microporous silica membranes, ${ }^{13}$ which may be beneficial to the transport of the light gases in the expired stream. It is known that the effective pore size of silica membranes can be readily tailored by sol-gel parameters, ${ }^{15,18,19}$ the number of coatings and calcination parameters. ${ }^{20,}{ }^{21}$ In general, for a certain sol solution, several coatings and a slow calcination process (i.e. ramping rate of 0.5$2{ }^{\circ} \mathrm{C} \min ^{-1}$ ) are needed to eliminate possible defects, which have a significant impact on the 
final membrane performance. Recently, preparing inorganic membranes with an RTP treatment (e.g. ramping rate $>100{ }^{\circ} \mathrm{C} \mathrm{min}^{-1}$ ) has been shown to also give promising separation performance, ${ }^{22-25}$ further reducing production time.

Single gas permeation tests $\left(\mathrm{CO}_{2}, \mathrm{O}_{2}, \mathrm{~N}_{2}\right.$ and sevoflurane) were initially carried out for both CTP and RTP membranes at $30{ }^{\circ} \mathrm{C}$. The RTP membrane, which showed better single gas separation performance was further assessed at $30{ }^{\circ} \mathrm{C}$ using a $\mathrm{CO}_{2} / \mathrm{N}_{2} /$ sevoflurane mixture (9.4 vol\%/84.6 vol\%/6 vol\%). Finally, the influence of water vapor on the mixed gas separation performance of the membrane was also investigated.

\section{Materials and Methods}

1,2-bis(triethoxysilyl)ethane (BTESE, 96\%) was purchased from Sigma-Aldrich and was used without further purification. The BTESE was added dropwise into a mixture of ethanol, water and $\mathrm{HCl}$ under vigorous stirring for 30 mins at room temperature. The molar composition was BTESE : $\mathrm{H}_{2} \mathrm{O}: \mathrm{HCl}: \mathrm{C}_{2} \mathrm{H}_{5} \mathrm{OH}$ was $1: 60: 0.1: 123$. The resultant solution was kept at $4^{\circ} \mathrm{C}$ until use. Tubular inorganic nanofiltration membranes composed of an $\alpha$-alumina support and $\mathrm{TiO}_{2} / \mathrm{ZrO}_{2}$ top-layer (supplied by Atech Innovations, GMBH, Molecular cut-off: $5 \mathrm{kDa}$, ID: $6 \mathrm{~mm}$, length: $100 \mathrm{~mm}$ ) were used as a membrane support to reduce BTESE membrane thickness and to provide mechanical strength.

The BTESE solution was coated on the inner side of the membrane support by a dip-coating method using a syringe pump with a withdrawal speed of $10 \mathrm{~cm} \mathrm{~min}{ }^{-1} \cdot{ }^{26}$ For the CTP treatment, the membrane was dried at $200{ }^{\circ} \mathrm{C}$ for 30 mins with a heating/cooling rate of $1^{\circ} \mathrm{C} \mathrm{min}-1$. For the RTP treatment, an oven was preheated to $200{ }^{\circ} \mathrm{C}{ }^{27}$. The membrane was put into the oven and kept for 30 mins, then it was removed using tongs directly, leading to a heating/cooling rate of $>100{ }^{\circ} \mathrm{C} \mathrm{min}{ }^{-1}$. The coating/thermal treatment process was repeated three times to eliminate possible defects on the membrane layer. Both membranes were then kept in a desiccator for 
further membrane performance testing. Hereafter, they were named as the CTP and the RTP membrane. For comparison, a commercial polydimethylsiloxane PDMS thin film composite membrane (Sulzer Pervap 4060) was also evaluated.

Initially, all membranes (i.e. PDMS, RTP and CTP membrane) were tested using a a constant volume and variable pressure apparatus as described elsewhere. ${ }^{28} \mathrm{CO}_{2}, \mathrm{O}_{2}$ and $\mathrm{N}_{2}$ permeances were tested at $100 \mathrm{kPa}$ feed pressure (absolute) and $30^{\circ} \mathrm{C}$. Sevoflurane permeance was tested at $20.6 \mathrm{kPa}$ (absolute) by evaporating sevoflurane liquid at $20{ }^{\circ} \mathrm{C}$ into a feed chamber that had previously been evacuated. The permeate side was under vacuum conditions before measurement and the permeance was calculated based on the pressure change on the permeate side.

The RTP membrane was further tested to evaluate its mixed gas separation performance and the influence of water vapor. Figure 2 shows the schematic diagram of the mixed gas permeation apparatus. The membrane module was kept in an oven at $30^{\circ} \mathrm{C}$. For the dry gas mixture, a $10 \%$ $\mathrm{CO}_{2} / \mathrm{N}_{2}$ mixture was bubbled through a sevoflurane vessel with controlled temperature $\left(-2{ }^{\circ} \mathrm{C}\right)$ to reach a final feed composition of $9.4 \% / 84.6 \% / 6 \%\left(\mathrm{CO}_{2} / \mathrm{N}_{2} /\right.$ sevoflurane $) . \mathrm{CO}_{2} / \mathrm{N}_{2}$ was used instead of $\mathrm{CO}_{2} / \mathrm{O}_{2}$ as $\mathrm{N}_{2}$ has a larger kinetic diameter (3.64 $\AA$ ) than $\mathrm{O}_{2}(3.46 \AA)$. The sevoflurane partial pressure was estimated from the supplier's product information ${ }^{29}$ and the work by Schenning et al. ${ }^{30}$ and also confirmed through simulation in Aspen Plus ${ }^{(\mathrm{c})}$. For the wet gas mixture, the above dry feed gas mixture was further bubbled through a water vapor generator to introduce a certain amount of water vapor. The water vapor relative humidity $(\mathrm{RH})$ on the feed side was controlled by adjusting the temperature of the water vapor generator. The membrane was tested at $20.1 \%, 40.8 \%$ and $55.4 \% \mathrm{RH}$. The feed pressure was controlled at $120 \mathrm{kPa}$ absolute pressure and the feed flow rate was set to $3 \mathrm{~L} \mathrm{~min}^{-1}$ to reduce the effect of concentration polarization. For the dry gas mixture experiments, the permeate pressure was controlled at 20 kPa using a back pressure valve. For the wet gas mixture tests, Helium was used as a sweep gas as the permeate flow rate was too low to maintain this permeate pressure. It is worth noting that 
such a sweep gas is not necessary for the full scale application as the membrane module would have a much larger surface area.

The water vapor relative humidity on the permeate side was measured by a humidity sensor (Vaisala HMT330 Series). An iced water cold trap was then used to condense this water vapor on the permeate side, with a downstream vacuum pump maintaining the permeate pressure at $20 \mathrm{kPa}$. Sevoflurane could not condense in this trap, as the partial pressure required in the permeate for condensation to occur $\left(8 \mathrm{kPa}\right.$ at $\left.0^{\circ} \mathrm{C}\right)$ would be greater than the feed partial pressure of $7.2 \mathrm{kPa}$ generated at $-2{ }^{\circ} \mathrm{C}$

The sevoflurane composition on the permeate side was analyzed using a Perkin Elmer FTIR (Fourier Transform Infrared Spectrometer) equipped with a CycloneTM gas cell accessory with a path length of $2 \mathrm{~m} .{ }^{31}$ Each spectrum was recorded in the range of $1000-4000 \mathrm{~cm}^{-1}$ with a resolution of $2 \mathrm{~cm}^{-1}$ and an average of 8 scans was used. A background scan was conducted under vacuum conditions before the measurement. An example of the sevoflurane spectrum is shown in the Supporting Information (Figure S1). The FTIR was calibrated against a sevoflurane/ $\mathrm{N}_{2}$ mixture reference $(0.07 \mathrm{vol} \%$ at $1 \mathrm{bar})$ in a range of 0.5 to $0.2 \mathrm{bar}$. At least three measurements were carried out at each pressure. The calibration curve was based on the peak area between 1450 and $1000 \mathrm{~cm}^{-1}$ and is shown in Supporting Information, Figure S2. Results from the FTIR analysis confirmed that sevoflurane had not condensed in the cold trap, as the measured permeate partial pressure was more than two orders of magnitude below the saturation partial pressure of $8 \mathrm{kPa}$.

The permeate flow rate was measured by a mass flow meter (Aalborg) with the calibration confirmed using a bubble flowmeter. The $\mathrm{CO}_{2}$ and $\mathrm{N}_{2}$ composition on the permeate side was analyzed by an Agilent 480 Micro gas chromatography (Micro GC) equipped with a Micromachined Thermal Conductivity Detector ( $\mu$ TCD) and a PoraPLOT U (PPU) column. 
Each data point was recorded 0.5-1 hour after changing the experimental conditions to ensure equilibrium had been achieved. Each single gas and mixed gas experiment was repeated five times to allow error margins to be established.

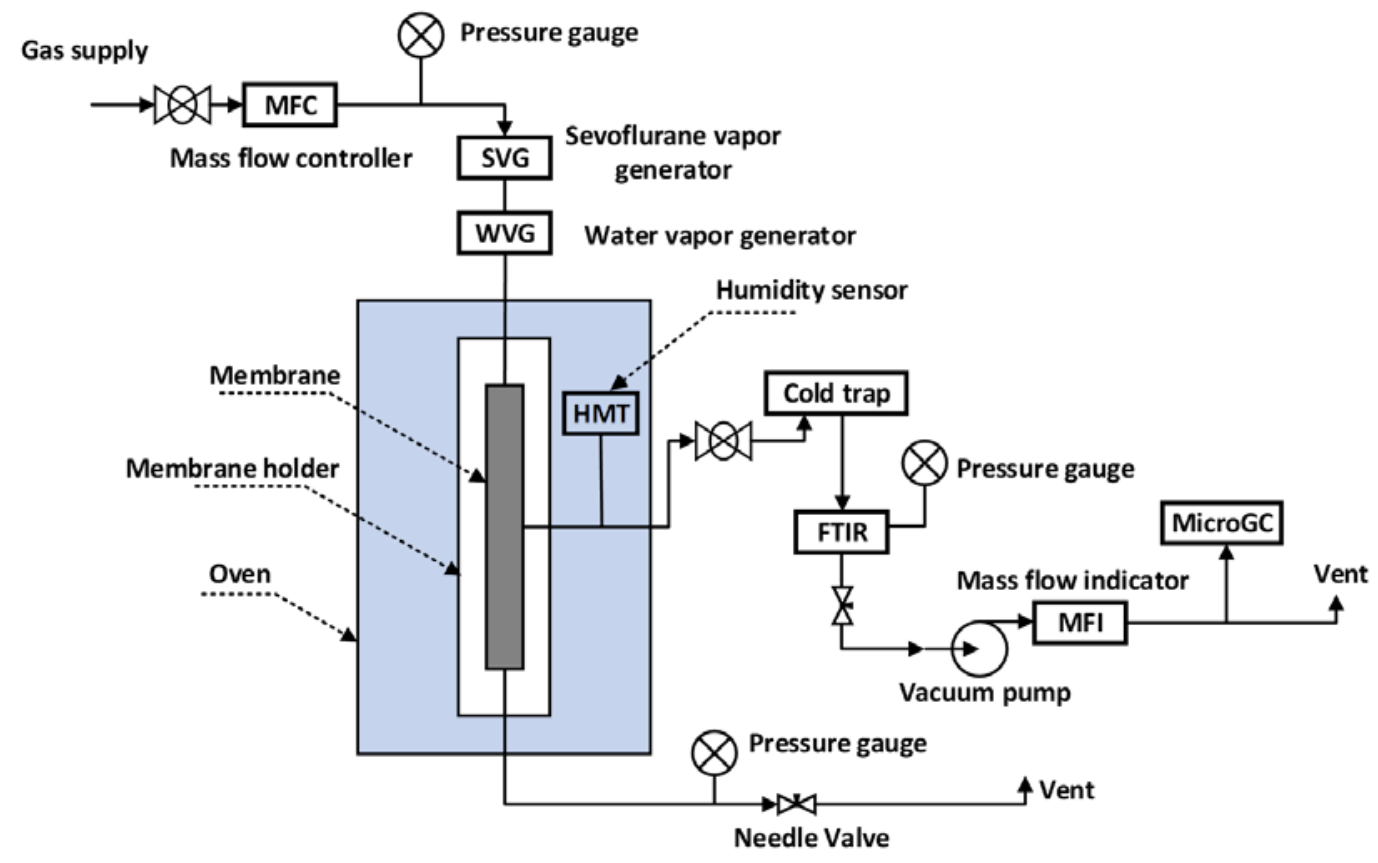

Figure 2: Schematic diagram of the mixed gas permeation apparatus. MFC= mass flow controller; SVG= sevoflurane vapor generator; WVG = water vapor generator; FTIR = Fourier Transform Infrared Spectrometer and MFI = mass flow indicator .

\section{Results and discussion}

Figure 3 shows the single gas permeances of $\mathrm{CO}_{2}, \mathrm{O}_{2}, \mathrm{~N}_{2}$ and sevoflurane of both the CTP and the RTP membrane at $30^{\circ} \mathrm{C}$. Both membranes show typical molecular sieving behaviour, with the gas permeances in the order of penetrant kinetic diameter, indicating the membranes were defect-free. It is also clear that the RTP membrane has higher permeance for all tested gases than the CTP membrane. The $\mathrm{CO}_{2}$ permeances were 700 and 4200 GPU for the CTP and the RTP membrane, while they were 500 and 850 GPU for $\mathrm{N}_{2}$. The permeances of sevoflurane were 
2.0 and 11 GPU, respectively. On the other hand, the $\mathrm{CO}_{2}, \mathrm{~N}_{2}$ and sevoflurane permeances of the PDMS membrane were 480, 65 and 550 GPU, respectively. The high permeance of sevoflurane may be attributed to its high critical temperature and confirms that a solubility selective material such as PDMS is not suitable for this separation.

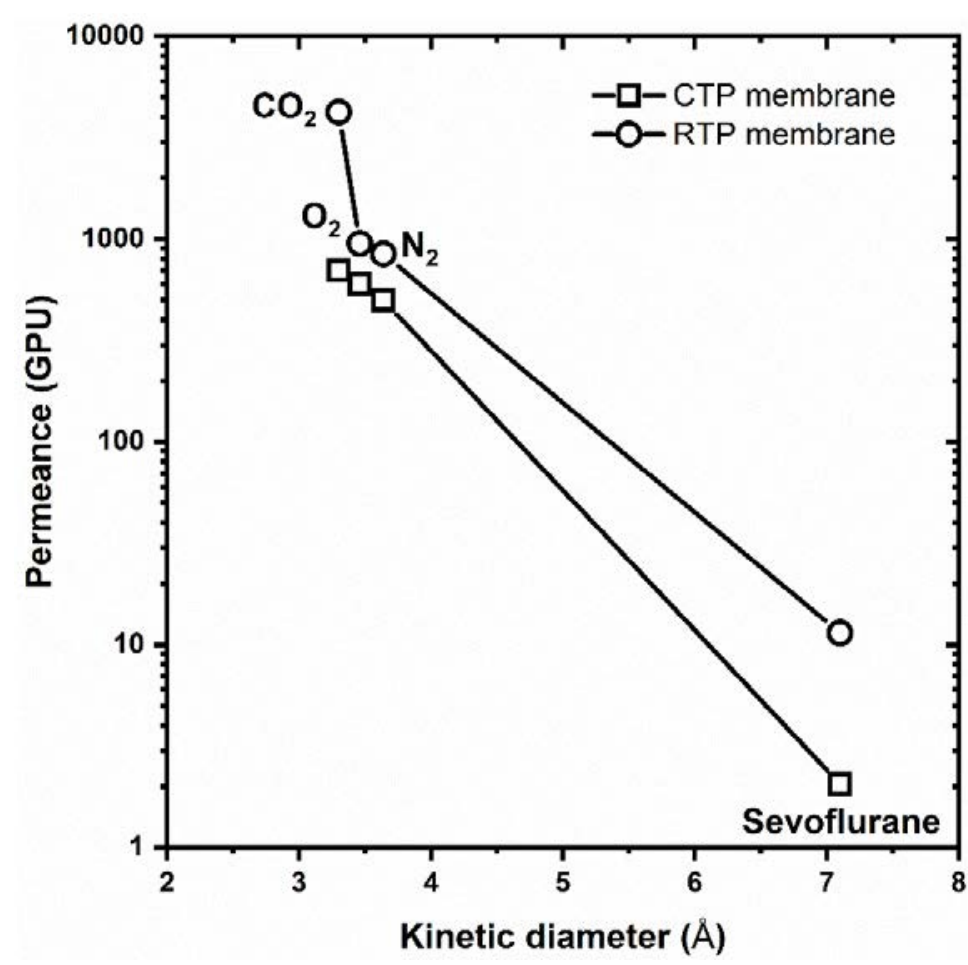

Figure 3: Single gas permeance of the CTP and RTP membrane as a function of kinetic diameter $\left(\mathrm{CO}_{2}: 3.3 \AA ; \mathrm{O}_{2}: 3.46 \AA ; \mathrm{N}_{2}: 3.64 \AA\right.$; critical diameter of $7.1 \AA$ was used for sevoflurane $\left.{ }^{11}\right)$. Note: the maximum experimental error is within $10 \%$ of each data point shown. Importantly, the $\mathrm{CO}_{2} /$ sevoflurane selectivity was 350 for the CTP membrane and 370 for the RTP membrane, indicating both membranes have similar molecular cut-off and can retain the anesthetic gas. The $\mathrm{CO}_{2} / \mathrm{N}_{2}$ selectivity was quite low for both membranes (i.e. 1.4 and 4.9 for the CTP and the RTP membrane) compared with typical BTESE membrane performance reported in the literature. ${ }^{16,17}$ For instant, Ren et al. ${ }^{16}$ has reported a $\mathrm{CO}_{2}$ permeance of 2300 GPU with $\mathrm{CO}_{2} / \mathrm{N}_{2}$ selectivity of 36 at $40{ }^{\circ} \mathrm{C}$ under 1 bar transmembrane pressure for a BTESE membrane calcined at $300{ }^{\circ} \mathrm{C}$. Yang et al. ${ }^{17}$ demonstrated a BTESE membrane with $\mathrm{CO}_{2}$ permeance of $3900 \mathrm{GPU}$ with $\mathrm{CO}_{2} / \mathrm{N}_{2}$ selectivity of 24 at $20{ }^{\circ} \mathrm{C}$ by employing a two-step hot 
coating method. The low $\mathrm{CO}_{2} / \mathrm{N}_{2}$ selectivity may be attributed to the relatively low calcination temperature (i.e. $200{ }^{\circ} \mathrm{C}$ ), leading to a lower degree of densification/condensation. ${ }^{20}$ Further, only three coatings were applied in our work, resulting in a broad pore size distribution. It is beneficial to have low $\mathrm{CO}_{2} / \mathrm{N}_{2}$ selectivity in the present case as we aim to only retain sevoflurane in the feed side, with minimal transport resistance to other gases, in particular $\mathrm{N}_{2}$. A larger membrane area is needed if $\mathrm{N}_{2}$ permeance is low, and this would be a limiting factor for the membrane design. This means that the percolative pathways that control the gas selectivity should be in the size range of $\mathrm{N}_{2}$ and sevoflurane rather than in that of $\mathrm{CO}_{2}$ and $\mathrm{N}_{2}$. It is worth noting that the thermal processing time was much shorter for the RTP membrane than the CTP membrane (30 mins versus 340 mins for each coating), making the fabrication process more productive. Hence, the RTP membrane was chosen for further investigation.
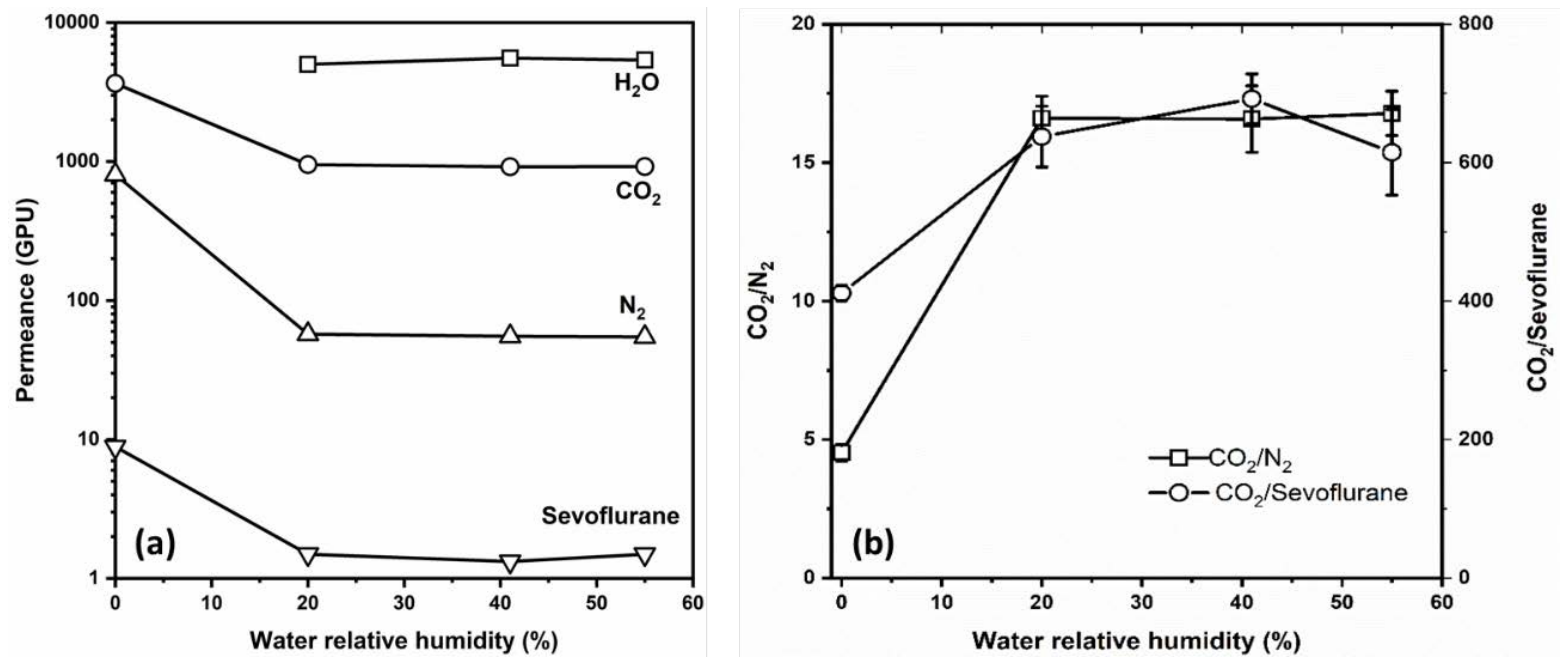
Figure 4: (a) gas permeances of the RTP membrane under mixed-gas conditions and (b) $\mathrm{CO}_{2} / \mathrm{N}_{2}$ and $\mathrm{CO}_{2} /$ sevoflurane selectivity as a function of water humidity. Note: the maximum experimental error is within $10 \%$ of each data point shown in Fig. 4(a).

As the operation of an anesthetic machine is under humid conditions, it is important to understand the mixed-gas separation performance and the influence of water vapor on the membrane performance. Figure 4(a) shows gas permeances of the membrane under dry and wet mixed gas conditions. For the dry mixture, the $\mathrm{CO}_{2}, \mathrm{~N}_{2}$ and sevoflurane permeances were 3650, 810 and 9 GPU, respectively. All values were slightly lower than those of the single gas 
permeance data shown in Fig. 3, which might be due to competitive sorption or hindered diffusion.

In a humid gas stream, the water vapor has higher permeance than $\mathrm{CO}_{2}$ as it has a smaller kinetic diameter and thus higher diffusivity and probably also higher solubility in silica (Figure 3). The permeance of all three other gases were significantly reduced by the presence of water vapor. When the feed humidity was $20.1 \%$, the $\mathrm{H}_{2} \mathrm{O}, \mathrm{CO}_{2}, \mathrm{~N}_{2}$ and sevoflurane permeances were 5000 , 950, 57 and 1.5 GPU, respectively.

The permeances remained almost constant when the relative humidity was further increased to $40.8 \%$ and $55.3 \%$. This means that the $\mathrm{N}_{2}$ permeance was reduced to $7 \%$ of the initial value under dry conditions, while the sevoflurane permeance was reduced to $17 \%$. The decrease of gas permeance is understandable as the membrane material is hydrophilic and porous. Water vapor can adsorb on the silica surface via hydrogen bonding with silanol groups. ${ }^{16,32,33}$ Moreover, water vapor can form clusters thus likely blocking the transport pathways of other gases, which has been reported in both inorganic and polymeric membranes. ${ }^{34-36}$ For example, Ren et al. ${ }^{16}$ reported that $\mathrm{CO}_{2}$ permeance of BTESE membrane was reduced by $99 \%$ at $83 \%$

$\mathrm{RH}$ at $40{ }^{\circ} \mathrm{C}$. It is not surprising that the reduction is more prominent than in our case $(74 \%$ reduction) as the membrane has a smaller pore size evidenced by its higher $\mathrm{CO}_{2} / \mathrm{N}_{2}$ selectivity. Moreover, their membrane was calcined at $300{ }^{\circ} \mathrm{C}$, hence fewer organic groups (more hydrophilic groups) can be expected on the membrane surface. Interestingly, the more stable $\mathrm{CO}_{2}$ permeance in this work was similar to the trend for a BTESO (bis(triethoxysilyl)octane) membrane ${ }^{16}$, which is expected to have a larger pore size and be less hydrophobic. These results clearly demonstrate that water vapor has a significant impact on the separation performance of the membrane, which should be taken into consideration during process design.

The influence of water vapor on $\mathrm{CO}_{2} / \mathrm{N}_{2}$ and $\mathrm{CO}_{2} /$ sevoflurane selectivity is shown in Figure 4(b). 
humid conditions (i.e. 20.1\%, 40.8\% and 55.3\% RH), while the $\mathrm{CO}_{2} /$ sevoflurane selectivity increased from 410 to above 600 . The increase is mainly because water has less impact on the $\mathrm{CO}_{2}$ permeance than $\mathrm{N}_{2}$ and sevoflurane.

As an example, if the gas in the breathing circuit was at $101 \mathrm{kPa}$ and contained 4 vol\% water vapor, 2 vol\% $\mathrm{CO}_{2}$ and 2 vol\% of sevoflurane, the permeate pressure was $10 \mathrm{kPa}$ and there was complete mixing on both sides of the membrane, these wet gas permeance values would lead to a permeate composition of approximately 26 vol\% water vapor, 11 vol\% $\mathrm{CO}_{2}$ and 0.04 vol\% sevoflurane (assuming the $\mathrm{O}_{2}$ permeance was identical to that of $\mathrm{N}_{2}$ ). The high concentrations of $\mathrm{CO}_{2}$ in the permeate can reduce the load on the $\mathrm{CO}_{2}$ absorber in the circuit, allowing this to be replaced less often, or for a smaller unit to be used. In itself this is of environmental benefit, as the loaded absorber and the soda lime/calcium carbonate it contains is currently sent to landfill. Similarly, the strong permeation of water vapor removes the excess produced by patient breathing to be removed. Conversely, the anesthetic is retained, reducing the volume that needs to be added and thus reducing both cost and greenhouse gas emissions. Indeed, it was estimated that the emissions of volatile anaesthetic agents worldwide are equivalent to the $\mathrm{CO}_{2}$ emissions from 1 million cars in $2010{ }^{37}$. Our results clearly demonstrate that membrane technology can minimize these emissions with minor costs. The use of a ceramic membrane is ideal within the hospital environment as it can be readily sanitized or sterilized. Nevertheless, the membrane needs to be tested in a real anesthetic circuit to evaluate its long term performance and its impact on the operation of the anesthetic machine. This will require careful adjustment of the pressure relief valves and pressure control valves within the anesthetic machine to ensure patient safety.

\section{Acknowledgements}

The authors acknowledge the financial support of the Australian and New Zealand College of Anaesthetists (ANZCA Grant No. 18/011) and from the Western Health (Melbourne) Foundation. 

also gratefully acknowledged.

\section{Supporting Information}

IR spectrum of sevoflurane (Figure S1); IR peak area of sevoflurane at $1450-1000 \mathrm{~cm}^{-1}$ as a function of gas cell pressure (Figure S2).

\section{References}

1. Sherman, J.; McGain, F., Environmental Sustainability in Anesthesia: Pollution Prevention and

2. Ryan, S. M.; Nielsen, C. J., Global warming potential of inhaled anesthetics: application to clinical use. Anesthesia \& Analgesia 2010, 111, (1), 92-98.

3. Fee, J.; Murray, J.; Luney, S., Molecular sieves: an alternative method of carbon dioxide removal which does not generate compound $A$ during simulated low - flow sevoflurane anaesthesia. Anaesthesia 1995, 50, (10), 841-845.

4. McNeil, M. V.; Wilfart, F. M.; Haelssig, J. B., Modelling hollow fiber membrane modules for anesthesia gas separation. Chemical Engineering Science 2018, 191, 479-489.

5. Wilfart, F. M.; McNeil, M. V.; Haelssig, J. B.; Hanafi, H.; Roach, D. C.; Maksym, G.; Schmidt, M. K., Validation and optimization of a membrane system for carbon dioxide removal in anesthesia circuits under realistic patient scenarios. Journal of Membrane Science 2020, 601, 117887.

6. Obuskovic, G.; Sirkar, K. K., Liquid membrane-based $\mathrm{CO} 2$ reduction in a breathing apparatus. Journal of Membrane Science 2012, 389, 424-434.

7. Ang, T. N.; Young, B. R.; Taylor, M.; Burrell, R.; Aroua, M. K.; Baroutian, S., Breakthrough analysis of continuous fixed-bed adsorption of sevoflurane using activated carbons. Chemosphere 2020, 239, 124839.

8. Hua, Y.; Gargiulo, N.; Peluso, A.; Aprea, P.; Eić, M.; Caputo, D., Adsorption Behavior of Halogenated Anesthetic and Water Vapor on Cr - Based MOF (MIL - 101) Adsorbent. Part I. Equilibrium and Breakthrough Characterizations. Chemie Ingenieur Technik 2016, 88, (11), 1730-1738. 9. Hua, Y.; Gargiulo, N.; Peluso, A.; Aprea, P.; Eić, M.; Caputo, D., Adsorption Behavior of Halogenated Anesthetic and Water Vapor on Cr - Based MOF (MIL - 101) Adsorbent. Part II. Multiple - Cycle Breakthrough Tests. Chemie Ingenieur Technik 2016, 88, (11), 1739-1745.

10. Abrahams, B. F.; Dharma, A. D.; Donnelly, P. S.; Hudson, T. A.; Kepert, C. J.; Robson, R.; Southon, P. D.; White, K. F., Tunable porous coordination polymers for the capture, recovery and storage of inhalation anesthetics. Chemistry-A European Journal 2017, 23, (33), 7871-7875.

11. Bucher, D.; Pasel, C.; Luckas, M.; Bentgens, J. r.; Bathen, D., Adsorption of inhalation anesthetics (fluranes and ethers) on activated carbons and zeolites at trace level concentrations. Journal of Chemical \& Engineering Data 2017, 62, (6), 1832-1841.

12. Wang, X.; Zhang, Y.; AndresGarcia, E.; Du, P.; Giordano, L.; Wang, L.; Hong, Z.; Gu, X.; Murad, S.; Kapteijn, F., Xenon Recovery by DD3R Zeolite Membranes: Application in Anaesthetics. Angewandte Chemie International Edition 2019, 58, (43), 15518-15525.

13. Kanezashi, M.; Yada, K.; Yoshioka, T.; Tsuru, T., Design of silica networks for development of highly permeable hydrogen separation membranes with hydrothermal stability. Journal of the American Chemical Society 2009, 131, (2), 414-415. 
14. Qi, H.; Han, J.; Xu, N., Effect of calcination temperature on carbon dioxide separation properties of a novel microporous hybrid silica membrane. Journal of membrane science 2011, 382, (1-2), 231-237.

15. Castricum, H. L.; Qureshi, H. F.; Nijmeijer, A.; Winnubst, L., Hybrid silica membranes with enhanced hydrogen and $\mathrm{CO} 2$ separation properties. Journal of membrane science 2015, 488, 121-128. 16. Ren, X.; Nishimoto, K.; Kanezashi, M.; Nagasawa, H.; Yoshioka, T.; Tsuru, T., CO2 permeation through hybrid organosilica membranes in the presence of water vapor. Industrial \& Engineering Chemistry Research 2014, 53, (14), 6113-6120.

17. Yang, X.; Du, H.; Lin, Y.; Song, L.; Zhang, Y.; Gao, X.; Kong, C.; Chen, L., Hybrid organosilica membrane with high $\mathrm{CO} 2$ permselectivity fabricated by a two-step hot coating method. Journal of Membrane Science 2016, 506, 31-37.

18. Qureshi, H. F.; Nijmeijer, A.; Winnubst, L., Influence of sol-gel process parameters on the micro-structure and performance of hybrid silica membranes. Journal of membrane science 2013, 446, $19-25$.

19. Kreiter, R.; Rietkerk, M. D. A.; Castricum, H. L.; van Veen, H. M.; ten Elshof, J. E.; Vente, J. F., Evaluation of hybrid silica sols for stable microporous membranes using high-throughput screening. Journal of Sol-Gel Science and Technology 2011, 57, (3), 245-252.

20. Song, H.; Wei, Y.; Qi, H., Tailoring pore structures to improve the permselectivity of organosilica membranes by tuning calcination parameters. Journal of Materials Chemistry A 2017, 5, (47), 24657-24666.

21. Niimi, T.; Nagasawa, H.; Kanezashi, M.; Yoshioka, T.; Ito, K.; Tsuru, T., Preparation of BTESEderived organosilica membranes for catalytic membrane reactors of methylcyclohexane dehydrogenation. Journal of membrane science 2014, 455, 375-383.

22. Choi, J.; Jeong, H.-K.; Snyder, M. A.; Stoeger, J. A.; Masel, R. I.; Tsapatsis, M., Grain boundary defect elimination in a zeolite membrane by rapid thermal processing. Science 2009, 325, (5940), 590593.

23. Stoeger, J. A.; Choi, J.; Tsapatsis, M., Rapid thermal processing and separation performance of columnar MFI membranes on porous stainless steel tubes. Energy \& Environmental Science 2011, 4, (9), 3479-3486.

24. Wang, D. K.; da Costa, J. C. D.; Smart, S., Development of rapid thermal processing of tubular cobalt oxide silica membranes for gas separations. Journal of membrane science 2014, 456, 192-201. 25. Kappert, E. J.; Nijmeijer, A.; Benes, N. E., Expeditious calcination of inorganic membranes by an instant temperature increment. Microporous and mesoporous materials 2012, 151, 211-215.

26. Liu, L.; Wang, D. K.; Kappen, P.; Martens, D. L.; Smart, S.; da Costa, J. C. D., Hydrothermal stability investigation of micro-and mesoporous silica containing long-range ordered cobalt oxide clusters by XAS. Physical Chemistry Chemical Physics 2015, 17, (29), 19500-19506.

27. Liu, L.; Ding, J.; Sarrigani, G. V.; Fitzgerald, P.; Merican, Z. M. A.; Lim, J.-W.; Tseng, H.-H.; Xie, F.; Zhang, B.; Wang, D. K., Enhanced catalyst dispersion and structural control of Co3O4-silica nanocomposites by rapid thermal processing. Applied Catalysis B: Environmental 2020, 262, 118246. 28. Duthie, X.; Kentish, S.; Powell, C.; Nagai, K.; Qiao, G.; Stevens, G., Operating temperature effects on the plasticization of polyimide gas separation membranes. Journal of membrane science 2007, 294, (1-2), 40-49.

29. Baxter Healthcare, Sevoflurane Product Information; 2014.

30. Schenning, K. J.; Casson, H.; Click, S. V.; Brambrink, L.; Chatkupt, T. T.; Alkayed, N. J.; Hutchens, M. P., Vapor Pressures of Anesthetic Agents at Temperatures Below $0^{\circ} \mathrm{C}$ and a Novel Anesthetic Delivery Device. Anesth Analg 2017, 124, (2), 473-479.

31. Lu, H. T.; Kanehashi, S.; Scholes, C. A.; Kentish, S. E., The potential for use of cellulose triacetate membranes in post combustion capture. International Journal of Greenhouse Gas Control 2016, 55, 97-104. 
32. Ren, X.; Kanezashi, M.; Nagasawa, H.; Tsuru, T., Preparation of organosilica membranes on hydrophobic intermediate layers and evaluation of gas permeation in the presence of water vapor. Journal of membrane science 2015, 496, 156-164. 33. Duke, M. C.; Da Costa, J. D.; Do, D. D.; Gray, P. G.; Lu, G. Q., Hydrothermally robust molecular sieve silica for wet gas separation. Advanced Functional Materials 2006, 16, (9), 1215-1220. 34. Chen, G. Q.; Kanehashi, S.; Doherty, C. M.; Hill, A. J.; Kentish, S. E., Water vapor permeation through cellulose acetate membranes and its impact upon membrane separation performance for natural gas purification. Journal of membrane science 2015, 487, 249-255. water/moisture on the performance of zeolite membrane and MMMs containing zeolite for gas separation; review. RSC Advances 2016, 6, (49), 42943-42961.

400 36. Poshusta, J. C.; Noble, R. D.; Falconer, J. L., Characterization of SAPO-34 membranes by water adsorption. Journal of membrane Science 2001, 186, (1), 25-40.

402 37. Sulbaek Andersen, M.; Sander, S.; Nielsen, O.; Wagner, D.; Sanford Jr, T.; Wallington, T., 403 Inhalation anaesthetics and climate change. British journal of anaesthesia 2010, 105, (6), 760-766. 


\section{University Library}

\section{- M M N E R VA A gateway to Melbourne's research publications}

Minerva Access is the Institutional Repository of The University of Melbourne

Author/s:

Liu, L;McGain, F;Kentish, SE

Title:

Recovery of Sevoflurane Anesthetic Gas Using an Organosilica Membrane in Conjunction with a Scavenging System

Date:

2021-02-09

Citation:

Liu, L., McGain, F. \& Kentish, S. E. (2021). Recovery of Sevoflurane Anesthetic Gas Using an Organosilica Membrane in Conjunction with a Scavenging System. ENVIRONMENTAL SCIENCE \& TECHNOLOGY, 55 (5), pp.3362-3367. https://doi.org/10.1021/acs.est.1c00159.

Persistent Link:

http://hdl.handle.net/11343/274931 